\title{
Engendering cultural responsive care: a reflective model for nurse education
}

\author{
Derek Chambers ${ }^{1}$, Susan Thompson ${ }^{2}$, Aru Narayanasamy ${ }^{3}$ \\ 1. School of Nursing Midwifery \& Physiotherapy, University of Nottingham, Derby, U.K. 2. School of Nursing Midwifery \& \\ Physiotherapy, University of Nottingham, Nottingham, U.K. 3. School of Nursing Midwifery \& Physiotherapy, University of \\ Nottingham, Nottingham, U.K.
}

Correspondence: Derek Chambers. Address: University of Nottingham, School of Nursing Midwifery \& Physiotherapy, Melbourne House, Royal Derby Hospital, Uttoxeter Road, Derby, DE22 3DT, U.K. Telephone: 44(0)-133-272-4900. Fax: 44(0)-133-237-0067. Email: derek.chambers@nottingham.ac.uk.

Received: May 11, 2012

DOI : $10.5430 /$ jnep.v3n1p70
Accepted: July 30, 2012

Published: January 1, 2013

URL: http://dx.doi.org/10.5430/jnep.v3n1p70

\section{Abstract}

A significant outcome of globalization has been a greater movement of peoples. As a consequence societies around the world are increasingly becoming multicultural. Multiculturalism, therefore, is a major characteristic of modern societies and one which has significant implications for health care delivery and health care systems. Many of these implications arise from differing health beliefs and values. Different cultural groups will, therefore, have values and attitudes consistent with that culture. Within health care the norms of the host culture tend to dominate resulting in ethnocentrism. This ethnocentric approach to delivery of health care has led to inequities, with immigrant groups reporting dissatisfaction with health care provision.

This paper explores the ways in which health belief systems and values are constructed. It then goes on to consider how differing health beliefs have led to health disparities, amongst differing cultural groups, within the United Kingdom. A model of reflection specifically designed to facilitate the exploration of health care values within a pre-registration nursing curriculum is proposed as one way of promoting culturally sensitive care within nursing students.

\section{Key words}

Culturally responsive, Immigration, Ethnocentrism, Health beliefs

\section{I ntroduction}

Globalisation is a key feature of the modern world a significant outcome of which has been a greater movement of peoples. Modern transport and the subsequent rise in economic migration and asylum seekers fleeing persecution have meant that societies around the world are increasingly becoming multicultural ${ }^{[1]}$.

Like many countries, the United Kingdom (UK) has seen a substantial increase in its immigrant populations from both within the European Union (EU) as well as from Non EU countries. Recent European statistics show that, in 2009, the UK had just over 4 million foreign-born citizens, which represents $6.6 \%$ of the UK's total population, placing the UK 40 th in the world for net migration ${ }^{[2]}$. 
A major contributing factor to this figure was the expansion of the EU, in May 2004, to include 10 New Member States (NMS). This made it possible for workers in some Central and Eastern European countries to take up work in the EU bringing immigration to the UK to new heights ${ }^{[3]}$. In addition to EU migrants there has been immigration from a host of other countries, particularly Africa and Asia. Many are voluntary migrants seeking a better lifestyle, whereas others are involuntary migrants, having to flee their own countries because of persecution, political upheaval, war and natural disasters in their own countries ${ }^{[3]}$.

Clearly such mass movement of the world's peoples has major implications for the world's health care systems. To some extent this has been acknowledged by the World Health Organisation (WHO), through its International Health Regulations, which promotes cross country co-operation in order to prevent and respond to acute public health risks which may cross borders and trigger pandemics ${ }^{[4]}$. As important as emergency measures are the implications of mass immigration extends to all aspects of health care, with host nations needing to ensure that their health care system is equipped to cater for people from different cultural backgrounds and their different disease profiles, cultural beliefs and health values. In other words there is an increasing need for health systems and professionals to become more culturally responsive.

Within the UK this is considered an important issue. A report to the UK's Home Office ${ }^{[5]}$ into the health care issues associated with asylum seekers recognised the need for health care professionals to become much more aware of the cultural and clinical backgrounds of ethnic groups. It goes on to suggest that good practice guidelines for differing ethnic groups should be developed. When the history of migration to the UK is considered it could be argued that having to make such a statement represents an indictment of the UK health system. After all mass immigration to the UK is by no means new. The decades that immediately followed the Second World War saw previously unprecedented immigration from the Caribbean and Indian sub-continent ${ }^{[6]}$. In retrospect the UK health care system has failed to consider the differing cultural health values that were inevitably held by these migrant populations. According to ${ }^{[7]}$, this was because the UK health care system was and still is grounded in western middle class values, which have subsequently produced a degree of ethnocentrism. This singular approach has been responsible for producing health disparities ${ }^{[8]}$.

\section{Manifestation of cultural health beliefs}

The issue of disparities is discussed in more detail later on in this paper; however it is important to acknowledge here that disparities in health occur due to a failure to recognise differing patient characteristics, which include differing cultural health values, beliefs and practices ${ }^{[5]}$. People from differing cultures will often: describe symptoms differently have different thresholds for seeking care and have unfamiliar beliefs, in comparison to the dominate culture, all of which will influence whether or not they comply with nursing care ${ }^{[9]}$. Evidence for this assertion comes from studies that have investigated how patients from differing cultures are likely to present their symptoms.

Many of these studies have taken place in the United States (US) where multiculturalism has been a feature of society for much longer than it has been in the UK and other parts of Europe. For example, Han et al ${ }^{[10]}$ found a significant difference in the way Chinese Americans described dyspnoea to that of the white population. A comparative study of the pain beliefs of Japanese and Euro-American Hobara ${ }^{[1]}$ reported that Japanese of both sexes were less prone to overt pain expression in comparison to Euro-Americans. These findings reflect the traditional Japanese cultural emphasis on stoicism and the desirability of concealing pain and emotions whereas the Euro-American culture puts a greater emphasis on the expression of personal feelings.

Within the field of mental health, Kleinman et al ${ }^{[12]}$ reported that because mental illness amongst the Chinese culture is stigmatized, minor psychiatric problems are commonly manifested by focusing on physical instead of psychological symptoms. Similarly Carpenter-Song et al ${ }^{[13]}$ found that Euro-Americans perceptions' of severe mental illness were aligned with professional disease-oriented perspectives and that they sought the advice and counsel of mental health professionals. In contrast African-American and Latino participants emphasised the non-biomedical interpretations of behavioural, , emotional, and cognitive problems. They were also more likely to be critical of mental health services. 
Although undertaken in the US these studies illustrate a fundamental message, which that is differing cultures will attribute differing meanings to symptoms and describe symptoms for the same health problem very differently. Such differences also apply to belief systems. For example Brown et al's ${ }^{[14]}$ investigation in the UK of Afro-Caribbean lay beliefs attitudes and understanding of diabetes, found a variety of beliefs about the causes of the disease. For example, insulin treatments were feared and diet- or tablet-controlled diabetes was seen by some as a mild form which did not warrant serious concern. The study also identified that there was some mistrust in the value of advice and treatment offered by professionals and a preference for natural treatments. Health professionals were generally praised but some felt the UK's National Health Service failed to cater properly for black people.

What these studies have highlighted is that the ways in which we explain health and illness are the products of the cultural influences during our upbringing and the society in which we live ${ }^{[12]}$. Health professionals, including nurses, will therefore, need to know and understand the complex interplay of their patients' values and beliefs and their concepts of health and illness if they are to provide culturally competent care ${ }^{[15]}$. It is, therefore important to understand how health values, beliefs and practices are formed.

\section{Formation of health values}

According to Parsons ${ }^{[16,17]}$ socialisation is the process by which human behaviour is shaped through experience in social situations. It is through the process of socialisation that we learn the norms and values of a given society ${ }^{[18]}$. One concept that is useful in understanding this process is Bourdieu's concept of 'habitus' ${ }^{[19]}$.

Bourdieu developed the concept of habitus as a way of describing how the social world becomes incorporated into a person's persona ${ }^{[20]}$. Habitus comes from a person's own history and primary socialisation which is then used to make sense of and to act within each new set of circumstances that they encounter. Consequently habitus acts as a classificatory basis for their values system. It is the resulting values that, according to Bourdieu, distinguish one social group from another. Different social groups, therefore, will make choices which are consistent with the values of that group ${ }^{\text {[21] }}$.

Consequently people's understanding of health and illness will be the product of their exposure to various discourses and experiences ${ }^{[22]}$. Hence each culturally diverse group will define health and illness differently, with most having a long and well-established tradition of folk health beliefs and practices ${ }^{[23]}$. These traditions of care will strongly impact on members' perceptions of what constitutes 'good care' ${ }^{[24]}$, which, in turn, influence expectations and perceptions of health care services ${ }^{[25]}$.

This point is particularly important when we consider that health professionals may project their own culturally based values and expectations [18] which in the UK are likely to be imbued with Anglo-Centric values ${ }^{[26]}$, onto patients from backgrounds different from their own with the unintended consequence being a perpetuation of ethnocentrism ${ }^{\text {[27] }}$.

According to Carballeira ${ }^{[28]}$ the formation of health values is also likely to lead to health professionals holding certain inappropriate cross-cultural attitudes towards people from minority communities (see Table 1).

Table 1. Cross cultural attitudes to minority groups (Adapted from Carballeira ${ }^{[28]}$ )

\begin{tabular}{ll}
\hline Predominant cultural attitude & Manifestation \\
\hline Superiority & $\begin{array}{l}\text { Practitioners believe client's culture is inferior and attempt to impose } \\
\text { their values and worldview }\end{array}$ \\
Incapacity & $\begin{array}{l}\text { Practitioners acknowledge cultural differences but are ill-equipped } \\
\text { to address them and therefore offer a standard intervention based on } \\
\text { dominant culture. } \\
\text { Pniversality }\end{array}$ \\
& $\begin{array}{l}\text { all patients alike. } \\
\text { and }\end{array}$ \\
\hline
\end{tabular}




\section{Disparities in the utilisation of health care services amongst differing ethnic groups}

This lack of understanding of cultural health values and the perpetuation of western values, may at least in part help explain the racial patterns in the use of the health service ${ }^{[29]}$. Evidence is emerging, from a number of countries including: Spain ${ }^{[30]}$, the United States ${ }^{[31]}$, Canada ${ }^{[32]}$ and the Netherlands ${ }^{[33,34]}$, which demonstrates that the use of health services is also lower, when compared with their non-immigrant counterparts ${ }^{[35]}$. Yet, care providers are seemingly oblivious to these disparities

Within the UK, evidence has emerged of fluctuation of satisfaction with health care services amongst the non-indigenous population when compared with the indigenous white population greater. The UK’s Department of Health's [36]Report on the self-reported experience of patients from ethnic groups identified that the reported experiences of some ethnic groups with UK health services are significantly less consistent than those reported by patients from the White British group. One essential conclusion made in the report is that:

'...the ethnic differences observed do not as a whole follow consistent patterns. Whilst in some areas certain groups are markedly less likely to give positive responses, there are other aspects of care where no differences are apparent, or where results are more likely to be positive than for the White British group. Furthermore, results vary considerably across ethnic groups and across healthcare settings. ${ }^{[37]}$

This inconsistency poses a problem when planning culturally responsive care. To be blunt one size does not fit all. This has added significance when the disease profiles for various ethnic groups are considered.

\section{Differential disease profiles of ethnic groups in the UK}

Within the UK incidence of some diseases differ significantly amongst some ethnic groups especially when compared to the indigenous 'white' population. For example diabetes is one of the most common long term diseases in the UK with its prevalence amongst the 'white' population at around $2.4 \%$, whereas in some minority groups it is between 3-5 times higher [5]. South Asian groups, specifically Pakistani, Bangladeshi and Indians, of both sexes, are 50\% more likely to have a heart attack or angina than men in the general population (National Health Service Health \& Social Care Information Centre 2005). Whereas males born in the Caribbean are 50\% more likely to die of stroke than the general population, but have much lower mortality to coronary heart disease ${ }^{[38]}$.

The predisposition of certain ethnic groups to higher prevalence of certain diseases or conditions is multifactoral. These factors include genetic disposition, but also environmental, social and cultural influences including health beliefs and health behaviours ${ }^{[39]}$. There is also evidence that the health of some ethnic groups deteriorates as they spend more time in the receiving society. The concept of 'acculturation'-the adoption of norms, values and behaviours that prevail in the receiving society - has been used to explain changes in the health behaviour of migrants that have negative consequences on health outcomes in the longer term ${ }^{[40-42]}$. Regardless of the cause such evidence illustrates that there is an urgent need for nurse education to better prepare student nurses to become culturally responsive practitioners ${ }^{[43]}$.

\section{Defining cultural competence}

Although widely used and despite a plethora of literature on the subject, the term 'cultural competence' is a contested one. Researchers have struggled with its definition and measurement. Consequently, understanding related to cultural competence is rather patchy and unsystematic.

Rosenjack-Burchum ${ }^{[44]}$ defines cultural competence as the development of knowledge and skill manifested in the synthesis of the key attributes of cultural awareness, cultural knowledge, cultural understanding, cultural sensitivity and 
cultural skill. However the problem with this definition is that it is possible to be considered culturally competent but still fail to respond to the differing health needs of culturally diverse groups.

\section{Promotion of cultural competence within nursing}

Leininger ${ }^{[45]}$ provided the first formal definitions of transcultural nursing and health-illness practices, beliefs and values. Today one of the most accepted definitions of cultural competence is the one developed by ${ }^{[46]}$. According to this definition, cultural competence is demonstrated when practitioners understand and appreciate differences in health beliefs and behaviours, recognise and respect variations that occur within cultural groups, and are able to adjust their practice to provide effective interventions for people from various cultures.

Suarez-Balcazar and Rodakowski ${ }^{[47]}$ believe that:

‘...becoming culturally competent is an on-going contextual, developmental and experiential process of personal growth that results in professional understanding and ability to adequately serve individuals who look, think and behave differently from us' (p15).

They go on to suggest ${ }^{[48]}$ that the process of becoming culturally competent can occur through:

'...repetitive engagements with diverse groups, by increasing one's critical awareness and knowledge, and/or by having opportunities for reflection and analysis about one's professional performance' (p.14).

But as we have already highlighted it does not follow that being culturally competent or culturally aware will lead to nurses being culturally responsive and as we have demonstrated it is only by responding to the health care needs of culturally diverse groups that nursing care will truly meet their needs.

This view is supported by Narayanasamy ${ }^{[49]}$ who criticises definitions such as Rosenjack-Burchum ${ }^{[44]}$ and SuarezBalcazar and Rodakowski ${ }^{[47]}$ for being overly simplistic. Narayanasamy ${ }^{[49]}$ refers to cultural competency as having a number of facets including: cultural awareness, skills of communication, responsiveness and sensitivity, avoidance of stereotypical assumptions about ethnicity, culture and promotion of anti-discriminatory practices. It involves cultural negotiation and compromise and promotion of cultural safety in practice. It is not necessarily about using cultural and religious fact files in responding to ethnicity and cultural needs ${ }^{[49]}$. Fact files knowledge may be assumed to be cultural competence and such knowledge may be applied indiscriminately based on assumptions about those fitting a cultural fit. Such essentialist approaches could be offensive and wholly inappropriate because there is no such thing as a typical culture which is fixed or frozen in time. Culture is an amalgamation of multi-factors and evolves and adapts over time.

An essential aspect of developing culturally responsive care is, therefore, to challenge the belief that one's way of life and view of the world are inherently superior, and desirable to others ${ }^{[45]}$. Central to this ethnocentrism is the assumption that one's world view is central to all reality, whereas ethnorelativism suggests that cultures are only really understood relative to one another ${ }^{[50]}$.

\section{The need to dispel cultural misconceptions}

When discussing cultural competence teaching, we cannot ignore commonly held perceptions in the UK population around migrants and especially asylum seekers. It would be naive to assume that nurses do not hold common negative perceptions such as migrants taking jobs from UK workers and abusing the UK benefit system. In the current recession with rising unemployment rates, it is even more important to tackle attitudes to migrants as a recent report has shown that the recession has seen a surge in opposition to immigration into the $\mathrm{UK}^{[51]}$, also that those seeking employment are the 
most active opponents of immigration ${ }^{[52]}$. Nurses are as influenced by such prevailing views as is any other member of society.

Therefore such perceptions need to be debated and the facts explored in a forum where fears and opinions can be expressed without censure. Otherwise educators will again be overlaying professional doctrine onto staunchly held and persistent values and opinions which having not been dealt with, are bound to surface when caring for this client group ${ }^{[18]}$. In the case of refugees and asylum seekers, some degree of understanding of the trauma undergone in their home country by asylum seekers may be useful, both to counter misconceptions, and also to gain an understanding of the possible psychological needs of this client group. For example between 5 and $30 \%$ will have suffered torture ${ }^{[53]}$ and a recent study of asylum seekers in the South of England showed that 55\% were receiving treatment for depression ${ }^{\text {[54] }}$.

Learning about different cultures may be very interesting, but learning fact by fact check lists of different cultures' health beliefs and values are not what are required. Not only would this lead to stereotyping of the culture concerned, but would be of little practical use unless nurses had routine contact with the particular cultures under discussion both to familiarise themselves with these values and also to observe variations in them which will be common in every society. When people settle in a new country there will be a period of adjustment. The new entrant will need to establish how that society works, its systems, social norms, its laws, services and how to access them etc. The speed of this adaptation is reliant on many factors which may include the presence of existing friends, family or migrant communities within the country who can act as a source of information and support, but also whether the host country commits resources to aid adaptation and possible assimilation.(Holland \& Hogg 2001) People remain individuals with some striving to maintain their culture and resisting assimilation, whilst others seek to assimilate and embrace the mainstream culture they now find themselves part of, the majority lying between these extremes ${ }^{[55]}$. There is therefore no 'quick fix' for nurses in the assessment of the cultural values of their clients. What is needed is a method of teaching cultural health values and beliefs which also encompasses a reflection on the nurses' understanding of culture and cultural differences.

\section{Developing cultural responsiveness through reflexivity}

It is our assertion that if nurses are to truly become culturally competent they must become more reflexive and learn to suspend their own cultural values and traditions and to mediate the discrepancies that may exist between their own knowledge and values and that of their patients. Only by achieving this will they go on to achieve mutually acceptable nursing outcomes ${ }^{[56,57]}$. Thus a fundamental step in becoming culturally responsive is exploration of our own values and culture and acknowledgement of our own biases ${ }^{[58]}$.

Nurse education, therefore, needs to find ways of enabling students to raise unconsciously held personal beliefs, so that they can be consciously inspected. In the past nurse education has sought to achieve this through the use of critical reflection and it is now fundamental aspect of nursing practice which is supported by an abundance of literature on the subject $^{[59,60,61]}$. Despite the plethora of literature and the best efforts of nurse educationalists studies that have investigated typical levels of reflection reached by nurses, when reflecting on practice, have overwhelmingly shown that nurses generally tend to reflect superficially, with lower levels of reflection predominating, and only occasionally reach the higher, more challenging levels of critical reflection ${ }^{[62,63]}$.

There are a number of reasons for this, not least the fact that true reflection is a time hungry activity that puts additional pressure on an already overcrowded curricula ${ }^{[64]}$ and demands of practice. Another fundamental reason for the lack of deep reflection is the way that critical reflections are perceived. Critical reflection is not simply a matter of thinking issues through in some rationalist manner or undertaking a cognitive post mortem, but should also involve understanding that the personal habitus may be a barrier that is resistant to change as it conforms to the values of the dominant culture. Thus there is a significant risk that by not considering the concept of habitus, the depth of critical reflection undertaken within nurse education programmes will not develop cultural competent nurses. 
What has emerged from the discussions is the need to recognise the role of value systems within nursing and how these may impact on patient care. What is required is a mechanism by which student nurses and registered practitioners are able to critically examine and reflect on both personally held and professionally embedded values. To this end we are proposing a new model of reflection that can be used as a tool to enhance nurse's cultural awareness. We have deliberately designed the model so that it can be used in a variety of reflective opportunities that can occur within clinical or classroom based scenarios.

\section{A Cultural awareness model of reflection}

The main aim of the model (see Figure 1) is to promote a shift in nurse education from a curriculum that fails to break down the ethnocentrism and cultural stereotyping to one that promotes better nursing care for cultural groups. The key activity required of nurses by the model is that of critical reflection. To facilitate the required depth of reflection the model draws on Schon's ${ }^{[65]}$ model of reflection.

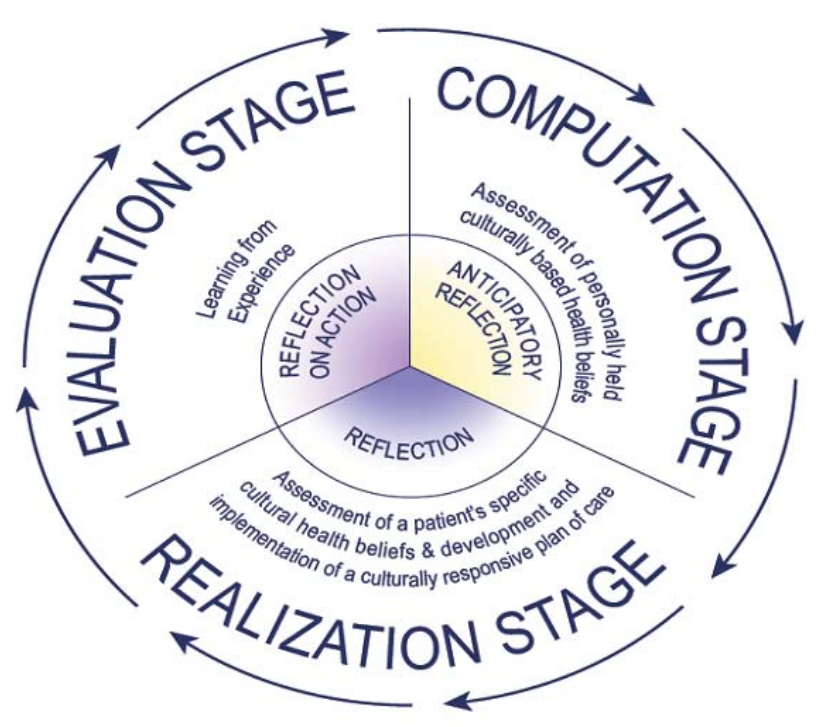

Figure 1. A cultural awareness model of reflection

\section{Schon's model of reflection}

Schon defines reflection in terms of action, both as reflection-in-action and reflection-on-action. Reflection-in-action requires a practitioner to think what they are doing while doing it. As the student attempts to interpret and understand the situation they are confronted with, they will ask themselves questions such as 'on what basis am I making this judgement?' 'What factors are influencing my rapport with this patient?' This includes the feelings that led to the adoption of a particular course of action and the way the problem is initially structured in the mind. All these are brought to the surface where the student criticises them, restructures and embodies them in further action. In this way reflection-in-action acts as a way of reshaping what we are doing whilst we are doing it. Reflection-on-action involves a cognitive post mortem approach within which the student looks back at their experiences to explore the implications of the processes used to generate the new understanding embodied in the outcomes of the action.

However what Schon's model does not do is encourage nursing students to reflect on their own presuppositions and the ways these are likely to construct the nurse/patient encounter before that encounter takes place. It is this reflection-priorto-action which is essential if student nurses are to become culturally aware and responsive. 


\section{Stages of the Model}

In developing the model, we were very cognisant that reflection can merely result in a change in the actions intended to lead to the same outcomes, what Argyris et al ${ }^{[67]}$ refer to as 'single loop learning', whereas what is needed is an examination of the relevance and propriety of the chosen outcome. It is this that involves a reflection on values and norms and by implication the social structures that are instrumental in their constitution. To aid the reflective process questions have been devised to aid critical thinking in each stage of the model (see Table 2).

Table 2. Questions aimed at facilitating reflection of cultural health values (adapted from Nairn et al ${ }^{[66]}$ )

\begin{tabular}{|c|c|c|c|}
\hline Stage & $\begin{array}{l}\text { Purpose of } \\
\text { Nursing Actions }\end{array}$ & $\begin{array}{l}\text { Level of } \\
\text { Reflection }\end{array}$ & Questions Aimed at the Reflective Process \\
\hline $\begin{array}{l}\text { Computation } \\
\text { Stage }\end{array}$ & $\begin{array}{l}\text { Assessment and } \\
\text { Comparison }\end{array}$ & $\begin{array}{l}\text { Reflection- } \\
\text { Prior-to-Practice }\end{array}$ & $\begin{array}{l}\text { *What are my values, assumptions and beliefs about health? } \\
\text { (For example, What does health mean to me?) } \\
\text { *Where have these beliefs come from? } \\
\text { * What social practices are expressed in these ideas of health? } \\
\text { * What are my experiences of health, how may they be similar to or } \\
\text { different from others? } \\
\text { ** What factors constrain my views about health? } \\
\text { * What factors may influence the way I provide care to this patient? } \\
\text { * How can I elicit my patients' beliefs about health? }\end{array}$ \\
\hline $\begin{array}{l}\text { Realisation } \\
\text { Stage }\end{array}$ & $\begin{array}{l}\text { Promote the } \\
\text { implementation of } \\
\text { culturally sensitive } \\
\text { \& responsive care }\end{array}$ & $\begin{array}{l}\text { Reflection-in-Ac } \\
\text { tion }\end{array}$ & $\begin{array}{l}\text { * Are the needs expressed by my patient reflecting felt needs or } \\
\text { normative needs? } \\
\text { * Am I coercing the client into working with normative needs? } \\
\text { * What are my client's goals with regard to their health? } \\
\text { * What factors exist that may serve to impede them achieving their } \\
\text { goals? } \\
\text { * Does the care I am giving adequately reflect my patient's cultural } \\
\text { needs and beliefs? } \\
\text { *How am I responding to my patients expressed cultural needs? }\end{array}$ \\
\hline $\begin{array}{l}\text { Evaluation } \\
\text { Stage }\end{array}$ & $\begin{array}{l}\text { Self-appraisal of the } \\
\text { interaction }\end{array}$ & $\begin{array}{l}\text { Reflection-on-A } \\
\text { ction }\end{array}$ & $\begin{array}{l}\text { * On what evidence did I base my actions? * Did my personal values } \\
\text { and beliefs influence the interaction? If so, how did they and what } \\
\text { can I do to limit this in future? } \\
\text { * Did I meet the patient's' agenda or my own? } \\
\text { * Did I facilitate the interaction or dictate? } \\
\text { * What did I do well? } \\
\text { * What aspects would I use again and why? } \\
\text { * What aspects would I do differently next time? }\end{array}$ \\
\hline
\end{tabular}

\section{Stage 1 The Computation Stage}

This stage occurs before any interaction between the nurse and the client has taken place. The level of reflection, therefore, is reflection-prior-to-practice. The aim of this stage is twofold. Firstly, it is intended to avoid nurses stereotyping their clients and divorcing them from their social circumstances by emphasising that health is a multidimensional concept that is mediated through culture, social class, gender and related experiences. In other words, it promotes the idea that health is socially constructed and as such is determined by the individual's lived experiences and it is the individual's interpretation of these that will determine the individual's perception of health.

The second aim of this stage is to avoid the client's health needs being defined by the nurse, a process defined as normative needs ${ }^{[68]}$, by instead focusing on the individual. By this we mean it encourages nurses to acknowledge that the personal 
reconstruction of experience is all pervasive and that they will take with them both similar, but in many instances very different prior experiences, to those of their clients. It is our own experiences and values that have the potential to shape profoundly the perceptions and interactions and become either facilitative or disruptive and counterproductive to the care process.

\section{Stage 2 The Realization Stage}

This is the 'doing' stage of the model, where the emphasis is on promoting the client's involvement in the care process. This is achieved by the nurse encouraging the clients to identify their felt needs and to verbalise them, that is, to change a felt need into an expressed one ${ }^{[68]}$.

Clearly, the issue for the nurse is accepting that a client's expressed needs may conflict with normative needs, hence it is essential that nurses perceive their clients in the wider context by developing an understanding of the way cultural groups think about health and the structures that exist and limit their options. What is taking place here, therefore, is an assessment of a patient's culturally determined beliefs, health values \& experiences, all of which may differ from those held by the nurse and or the dominant health care system. Once recognised these provide the basis for the adaptation of care in order to make care culturally sensitive. The reflection that takes place at this stage of the model is reflection-in-action.

\section{Stage 3 The Evaluation Stage}

In general, the purposes of evaluation are to diagnose problems, weaknesses and strengths. It can therefore be defined as a process of description and judgement, conducted for the purpose of determining a programme's effectiveness ${ }^{[68]}$. A concern we had with self-evaluation is that it can easily become self-destructive by focusing solely on self-criticism, thereby eroding confidence. This situation is heightened by the negative way in which reflection on practice is frequently perceived. Thus the questions used to guide this aspect of reflection are there to promote the positive aspects of the encounter as well as encouraging the search for constructive ways of providing and enhancing culturally sensitive care.

\section{Conclusion}

Increasing globalization has led to a substantial increase in immigration. This has resulted in the need for nurses to deliver culturally sensitive care to ever widening diverse patient groups. It is incumbent on nurse education and curriculum planners to ensure that student nurses are culturally aware, this, in turn will promote a degree of cultural competence. We have argued that one way this can best be achieved is through the critical reflection of personal values systems. The combined use of the proposed model and a selection of specific questions create a framework within which this can take place. The model can be used to facilitate individual and group based reflection sessions such as clinical supervision or in class room based work.

It is proposed that such reflection on our own judgments, agenda setting, and social practices in comparison to those of patients from other cultural groups can help bridge the gap between ethnocentric and culturally sensitive care.

\section{References}

[1] United Nations Population Fund. International migration and the millennium development goals. Selected papers of the UNFPA Expert Group. 2005.

[2] Smith L. Immigration: How the UK compares to other EU countries [Internet]. 2010. Available from: http://www.aboutimmigration.co.uk/how-uk-compares-other-eu-countries.html. Accessed $25^{\text {th }}$ June 2011.

[3] Helman C, G. Culture, health and illness. $5^{\text {th }}$ Edition Hodder Arnold London.2007.

[4] World Health Organisation. International Health Regulations. WHO Lyon.2005. 
[5] Johnson M, R, D., Biggerstaff D., Clay D., Collins G., Gumber A., Hamilton M., et al. Racial and ethnic inequalities: a critical review of the evidence. Report for the Home Office. Centre for Evidence in Ethnicity Health \& Diversity. Mary Seacole Research Centre De Montfort University and Warwick University Medical School. 2004.

[6] Taylor G. Migrants and refugees. In Transcultural health \& social care: Development of culturally competent practitioners. Papadopoulos I. (Editor.). Churchill Livingstone London. 2006.

[7] Wilson-Covington, I. Cultural competence for critical care nursing practice. Critical Care Nursing of North America. 2001; 13(4): 521-530.

[8] Betancourt, J., R. Green, A, R., Carrillo, J, E., Park, E, R. Cultural competence and health care disparities: key perspectives and trends. Health Affairs. 2005; 24(2):499-505. PMid:15757936 http://dx.doi.org/10.1377/hlthaff.24.2.499

[9] Leininger M. M., McFarland M, R. Culture care diversity and universality: A worldwide nursing theory (2 ${ }^{\text {nd }}$ edition). Jones \& Bartlett London. 2006.

[10] Han, J. Zhu Y. Li S., Chen, X., Put, C., Van de Woestijne, et al. Respiratory Complaints in Chinese Cultural and Diagnostic Specificities. Chest 2005; 127: 1942-1951. PMid:15947306 http://dx.doi.org/10.1378/chest.127.6.1942

[11] Hobara, M. Beliefs about appropriate pain behaviour: Cross-cultural and sex differences between Japanese and Euro-Americans. European Journal of Pain. 2005:389-393. PMid:15979019 http://dx.doi.org/10.1016/j.ejpain.2004.09.006

[12] Kleinman A., Eisenberg, L., Good B. Culture, illness, and care: clinical lessons from anthropologic and cross-cultural research. Journal of Life Learning in Psychiatry. 2006; 4 (1): 140-149.

[13] Carpenter-Song E., Chu W., Drake R, E., Ritsema M., Smith B., Alverston H. Ethno-cultural variations in the experience and meaning of mental illness and treatment: implications for access and utilization. Transcultural Psychiatry. 2010; 47(2): $224-251$. PMid:20603387 http://dx.doi.org/10.1177/1363461510368906

[14] Brown K. Avis, M. Hubbard, M. Health beliefs of African-Caribbean people with type 2 diabetes: a qualitative study. British Journal of General Practice. 2007; 57 (539): 461-469. PMid:17550671

[15] Wear D. Insurgent multiculturalism: rethinking how and why we teach culture in medical education. Academic Medicine. 2003; 78 (6):549-554. PMid:12805032 http://dx.doi.org/10.1097/00001888-200306000-00002

[16] Parsons T. The Social System Routledge. London. 1970.

[17] Parsons T. Definitions of health and illness in light of American values and social structures. In Jaco. E, G. (ed.) Patients, phyusicians and illness: a source book of behavioural science and health. Free Press New York. 1979.

[18] Chambers D. Narayanasamy A. A discourse and Foucauldian analysis of nurses health beliefs: Implications for nurse education. Nurse Education Today. 2007; 28(2):155-162. PMid:17452065 http://dx.doi.org/10.1016/j.nedt.2007.03.009

[19] Bourdieu P. The Field of cultural production or the economic world reversed. In Contemporary sociological theory. Calhoun, C. Gerteis J. Moody J. Pfaff S. Virk I. (eds.) Blackwell Publishing. Oxford.1993.

[20] Bourdieu P. Outline of a theory of practice. Cambridge University Press. Cambridge.1977.

[21] Bourdieu P. The Logic of Practice. Cambridge: Polity.1990.

[22] Barry A, M., Yuill C. Understanding health: a sociological introduction. Sage Publications. London. 2002.

[23] Kavangh K. Kennedy, P. Promoting cultural diversity: Strategies for health care professionals. Sage. London.1992.

[24] Cooper TP. Culturally appropriate care: optional or imperative. Advanced Practice Nursing Quarterly. 1996; 2(2):1-6.

[25] Holland K., Hogg C. Cultural awareness in nursing and health care. Arnold London.2001.

[26] Laird S, E. Teaching social work as a foreign language: a White European at an African university. Teaching in Higher Education. 2007; 11(3): 381-386. http://dx.doi.org/10.1080/13562510600680970

[27] Imes S., Landry D. Don't underestimate the power of culture. Scientific Nursing. 2002; 19(4): 172-176. PMid:12616779

[28] Carballeira N. The LIVE and LEARN Model for culturally competent family services. The Source. 1996; 6(2): 4-12.

[29] Szczepura A. Access to health care for ethnic minority populations. Postgrad Medical Journal.2005; 81: 141-147. PMid:15749788 http://dx.doi.org/10.1136/pgmj.2004.026237

[30] Carrasco-Garrido P., Gil De Miguel A., Herna'ndez Barrera V., Jime' nez-Garcı́a R. Health profiles, lifestyles and use of health resources by the immigrant population resident in Spain. European Journal of Public Health. 2007; 17(5): 503-507. PMid:17251304 http://dx.doi.org/10.1093/eurpub/ckl279

[31] Nandi A., Galea S., Lopez G., Nand V., Strongarone S., Ompad D.C. Access to and Use of Health Services Among Undocumented Mexican Immigrants in a US Urban Area. American Journal of Public Health. 2008; 98 (11): 2011-2020. PMid:18172155 http://dx.doi.org/10.2105/AJPH.2006.096222

[32] Whitley R., Kirmayer L. J., Groleau D. Understanding immigrants' reluctance to use mental health Services: a qualitative study from Montreal, Canadian Journal of Psychiatry. 2006; 51: 205-209. PMid:16629344 
[33] Uiters E. Deville, W, L, J, M., Foets, M., Groenewegen, P, P. Use of health care services by ethnic minorities in The Netherlands: do patterns differ? European Journal of Public Health. 2006; 16(4): 388-393. PMid:16641158 http://dx.doi.org/10.1093/eurpub/ckl040

[34] Stronks K, J., Ravelli A, C, J., Reijneveld S, A. Immigrants in the Netherlands: equal access for equal needs? Journal of Epidemiology and Community Health. 2001; 55:701-707. http://dx.doi.org/10.1136/jech.55.10.701

[35] Scheppers E., van Dongen E. Dekker J., Geertzen J., Dekker, J. Potential barriers to the use of health services among ethnic minorities: a review. Family Practice. 2006; 23(3): 325-348. PMid:16476700 http://dx.doi.org/10.1093/fampra/cmi113

[36] Department of Health. Report on the self-reported experience of patients from black and minority ethnic groups. Department of Health. London. 2009.

[37] National Health Service Health \& Social Care Information Centre. Health Survey for England 2004: The Health of Minority Ethnic Groups-headline tables. NHS Health and Social Care Information Centre, Public Health Statistics. London.2005.

[38] Parliamentary Office of Science and Technology. Ethnicity and Health. Postnote January No 276 Parliamentary Office of Science and Technology. London. 2007.

[39] Winkelman M. Culture \& health: applying medical anthropology. Jossey-Boss. San Francisco.2009.

[40] Zaman M.J.S, Mangtani P. 'Changing disease patterns in South Asians in the UK', Journal of the Royal Society of Medicine. 2007; 100: 254-5. PMid:17541088 http://dx.doi.org/10.1258/jrsm.100.6.254

[41] Gilbert P. and Khokhar S. 'Changing dietary habits of ethnic groups in Europe and implications for health', Nutrition Reviews. 2008; 66, 4: 203-15. PMid:18366534 http://dx.doi.org/10.1111/j.1753-4887.2008.00025.x

[42] Hawkins, S., Lamb K., Cole, T.J., Law C. 'Influence of moving to the UK on maternal health behaviours: prospective cohort study', British Medical Journal. 2008; 336: 1052-5. PMid:18403500 http://dx.doi.org/10.1136/bmj.39532.688877.25

[43] Cowan D, T., Norman I. Cultural competence in nursing: new meanings. Journal of Transcultural Nursing. $2006 ; 17$ (1): $82-88$. PMid:16410440 http://dx.doi.org/10.1177/1043659605281976

[44] Rosenjack-Burchum J, L. Cultural competence: An evolutionary perspective. Nursing Forum. 2002; 37 (4): 13 -23.

[45] Leininger, M, M. Transcultural nursing: concepts and practice. John Wiley. New York. 1978.

[46] Camphinha-Bacote J. A model and instrument for addressing cultural competence in health care. Journal of Nurse Education. 1999; 38: 203-207. PMid:10438093

[47] Suarez-Balcazar Y., Rodakowski J. Becoming a culturally competent occupational therapy practitioner. OT Pract. 2007; 12:14-17.

[48] Suarez-Balcazar Y., Rodawoski J., Balcazar F., Taylor-Ritzler T., Portillo N., Barwacz D., et al. Perceived levels of cultural competence among occupational therapists. American Journal of Occupational Therapy. 2009; 63: 498-505. PMid:19708479 http://dx.doi.org/10.5014/ajot.63.4.498

[49] Narayanasamy, A. Spiritual Care and Transcultural Care Research. Quay London.2006.

[50] Hammer, M, R. Bennet, M, J. Wiseman, R. Measuring intercultural sensitivity: International Journal of Intercultural Relations. 2003; 27: 421-443

[51] Searchlight Educational Trust Report: Fear and Hope. Searchlight Educational Trust. London. 2010.

[52] Card D., Dustmann C., Preston, I. Understanding attitudes to immigration: The migration and minority module of the first European Social Survey. Centre for research and analysis of migration. Discussion Paper No03/05. London.2005.

[53] British Medical Association. Asylum seekers-meeting their health care needs. British Medical Association. London.2002.

[54] Dumper H., Malfait R., Flynn, N. Mental Health, Destitution \& Asylum-Seekers. NIMHE (National Institute of Mental Health in England), South of England Refugee \& Asylum Seeker Consortium. London.2006.

[55] Ferguson B., Browne E. Health Care and Immigrants: A guide for the helping professions MacLennan and Petty Artarmon. New South Wales. 1991.

[56] DeSantis L. Making anthropology clinically relevant to nursing care. Journal of Advanced Nursing. 1994; 20 (4): 707-715. PMid:7822607 http://dx.doi.org/10.1046/j.1365-2648.1994.20040707.x

[57] Greipp ME. Culture and ethics: a tool for analysing the effects of biases on the nurse-patient relationship. Nursing Ethics: an International Journal for Health Care Professionals. 1995; 2(3): 211-221.

[58] Kagawa-Singer M. Addressing issues for early detection and screening in ethnic populations. Oncology Nursing Forum.1997.

[59] Gibbs G. Learning by doing: a guide to teaching \& learning methods. Oxford Further Education Unit. Oxford Polytechnic. 1998.

[60] Johns C. Becoming a reflective practitioner: a reflective \& holistic approach to clinical nursing, practice development \& clinical supervision. Blackwell Science Oxford.2000.

[61] Rolfe G., Freshwater D., Jasper M. Critical reflection in nursing \& the helping professions: a user’s guide. Palgrave-Macmillan. Basingstoke. 2001. 
[62] Liimatainen L., Poskiparta M., Karhila P. \& Sjogren A. The development of reflective learning in the context of health counselling and health promotion through nurse education. Journal of Advanced Nursing. 2001; 34 (5): 648-658. PMid:11380733 http://dx.doi.org/10.1046/j.1365-2648.2001.01794.x

[63] Jensen S. \& Joy C. Exploring a model to evaluate levels of reflection in Baccalaureate Nursing Student' Journals. Journal of Nursing Education. 2005; 44(3): 139-142. PMid:15787024

[64] Dalley K., Candela L., Benzel-Lindley J. Learning to let go: the challenge of de-crowding the curriculum. Nurse Education Today. 2008; 28: 62-69. PMid:17397973 http://dx.doi.org/10.1016/j.nedt.2007.02.006

[65] Schon D. Educating the reflective practitioner Jossey-Boss San Francisco.1987.

[66] Nairn S, Chambers D, Thompson S, McGarry J, Chambers K. Reflexivity and habitus: opportunities and constraints on transformative learning. Nursing Philosophy. 2012; 13(3): 189-201.

[67] Argyris C. Strategy Change \& Defensive Routines. Pitman. Boston.1985.

[68] Ewles L., Simnett I., Promoting health: a practical guide $5^{\text {th }}$ Edition. Bailliere Tindall. Edinburgh. 2003. 